\title{
Prenatal Opioid Exposure and Intermittent Hypoxemia in Preterm Infants: A Retrospective Assessment
}

\begin{abstract}
Elie G. Abu Jawdeh ${ }^{1 *}$, Philip M. Westgate ${ }^{2}$, Amrita Pant $^{1}$, Audra L. Stacy ${ }^{3}$, Divya Mamilla ${ }^{4}$, Aayush Gabrani ${ }^{5}$, Abhijit Patwardhan ${ }^{6}$, Henrietta S. Bada ${ }^{1}$ and Peter Giannone ${ }^{1}$

'Division of Neonatology, Department of Pediatrics, University of Kentucky, Lexington, KY, United States, ${ }^{2}$ Department of Biostatistics, College of Public Health, University of Kentucky, Lexington, KY, United States, ${ }^{3}$ College of Medicine, University of Kentucky, Lexington, KY, United States, ${ }^{4}$ Children's Hospital of Michigan, Detroit, MI, United States, ${ }^{5}$ Department of Pediatrics, New Jersey Medical School, Newark, NJ, United States, ${ }^{6}$ Department of Biomedical Engineering, College of Engineering, University of Kentucky, Lexington, KY, United States
\end{abstract}

Introduction: Intermittent hypoxemia $(\mathrm{H})$ is defined as episodic drops in oxygen saturation $\left(\mathrm{SpO}_{2}\right)$. Preterm infants are at increased risk for $\mathrm{IH}$ due to their immature respiratory control/apnea of prematurity. The clinical relevance of $\mathrm{H}$ is a relatively new observation with rising evidence linking $\mathrm{IH}$ to neonatal morbidities and long-term impairment. Hence, assessing factors that influence $\mathrm{H}$ in preterm infants is imperative. Given the epidemic of

OPEN ACCESS

Edited by:

Po-Yin Cheung,

University of Alberta, Canada

Reviewed by:

Christoph Martin Rüegger, University of Zurich, Switzerland

Roland H. Hentschel,

Universitätsklinikum Freiburg,

Germany

*Correspondence:

Elie G. Abu Jawdeh elie.abujawdeh@uky.edu

Specialty section:

This article was submitted to

Neonatology,

a section of the journal

Frontiers in Pediatrics

Received: 04 August 2017 Accepted: 10 November 2017 Published: 06 December 2017

Citation:

Abu Jawdeh EG, Westgate $P M$

Pant A, Stacy AL, Mamilla D,

Gabrani A, Patwardhan A, Bada HS and Giannone P (2017) Prenatal Opioid Exposure and Intermittent Hypoxemia in Preterm Infants: A Retrospective Assessment. Front. Pediatr. 5:253. doi: 10.3389/fped.2017.00253 opioid misuse in the USA, there is an urgent need to understand the impact of prenatal opioid exposure on neonatal outcomes. Hence, we wanted to assess the relationship between isolated prenatal opioid exposure and $\mathrm{IH}$ in preterm infants.

Methods: In order to accurately calculate $\mathrm{IH}, \mathrm{SpO}_{2}$ data were prospectively collected using high-resolution pulse oximeters during the first 8 weeks of life in preterm infants less than 30 weeks gestational age. Data related to prenatal opioid misuse were retrospectively collected from medical charts. Infants with tobacco or poly-drug exposure were excluded. The primary outcome measure is percent time spent with $\mathrm{SpO}_{2}$ below $80 \%$ (\%time- $\mathrm{SpO}_{2}<80$ ). The secondary outcome measure is the number of severe $\mathrm{HH}$ events/week with $\mathrm{SpO}_{2}$ less than $80 \%\left(\mathrm{H}-\mathrm{SpO}_{2}<80\right)$.

Results: A total of 82 infants with isolated opioid exposure $(n=14)$ or who were unexposed $(n=68)$ were included. There were no significant differences in baseline characteristics between opioid exposed and unexposed groups. There was a statistically significant increase of $0.23(95 \% \mathrm{Cl}: 0.03,0.43, p=0.03)$ in mean of the square root of \%time- $\mathrm{SpO}_{2}<80$. The number of $\mathrm{IH}-\mathrm{SpO}_{2}<80$ events was higher in the opioid exposed group (mean difference $=2.95,95 \% \mathrm{Cl}$ : $-0.35,6.25, p$-value $=0.08$ ), although statistical significance was not quite attained.

Conclusion: This study shows that preterm infants prenatally exposed to opioids have increased $\mathrm{IH}$ measures compared to unexposed infants. Interestingly, the increased $\mathrm{IH}$ in the opioid exposed group persists beyond the immediate postnatal period.

Keywords: prenatal, opioid exposure, opiates, intermittent hypoxemia, apnea, preterm infants

Abbreviations: GA, gestational age; IH, intermittent hypoxemia; NICU, neonatal intensive care unit; SIDS, sudden infant death syndrome; $\mathrm{SpO}_{2}$, oxygen saturation; THC, tetrahydrocannabinol. 


\section{INTRODUCTION}

Intermittent hypoxemia (IH) is defined as brief, episodic drops in oxygen saturation $\left(\mathrm{SpO}_{2}\right)(1,2)$. Preterm infants are at increased risk for IH due to their respiratory control instability/apnea of prematurity superimposed on immature lung structure/function. $\mathrm{IH}$ in preterm infants can persist beyond discharge from the neonatal intensive care unit (NICU) (3). Brief episodes of oxygen desaturations may seem clinically insignificant, but these IH episodes, occurring up to hundreds of times per day, have a cumulative effect on neonatal morbidity and mortality. There is ample evidence showing a significant effect of $\mathrm{IH}$ on neurocognitive handicap, decreased neuronal integrity, increased inflammation and oxidative stress, and impaired growth $(4,5)$. Furthermore, IH has been linked to severe retinopathy of prematurity and long-term neurodevelopmental impairment such as worse language and motor outcomes (2, 6-9). The clinical relevance of $\mathrm{IH}$ is a relatively new observation with the advent of high-resolution pulse oximeters and assessing factors that influence $\mathrm{IH}$ is imperative.

There is a rise in substance misuse in the USA reaching a nationwide epidemic (10-15). There is an urgent need to understand the impact of prenatal opioid exposure on neonatal outcomes (5). Opioid exposure is associated with long-term neurobehavioral and developmental impairment in infants (16-23). Opioids are known to suppress breathing and respiratory effort especially in neonates (24). Since most mothers who misuse opioids have also been found to smoke and use poly-drugs that affect breathing pattern, it has been challenging to assess the isolated effect of prenatal opioid exposure on respiratory outcomes. Prenatal tobacco exposure alters respiratory control and worsens lung function (25-29). Prenatal exposure to other illicit drugs such as cocaine perturbs maturation of respiratory control, resulting in disruption of postnatal respiration (30). Only few studies were able to assess the effect of isolated opioid exposure on neonatal respiratory outcomes. However, these studies included mostly later preterm and term infants or were limited to short monitoring times and small sample sizes (31, 32). In this study, we utilize continuous high-resolution pulse oximeters to assess the relationship between isolated prenatal opioid exposure and $\mathrm{IH}$ in preterm infants during the first 2 months of life.

\section{MATERIALS AND METHODS}

\section{Study Design and Data Collection}

Oxygen saturation data were prospectively collected from 130 preterm infants less than 30 weeks gestational age (GA) admitted to our level 4 NICU between November 2014 and April 2017. We used high-resolution pulse oximeters (Radical 7: Masimo, Irvine, CA, USA) set at $2 \mathrm{~s}$ averaging time and $1 \mathrm{~Hz}$ sampling rate to continuously monitor patients during the first 8 weeks of life. In order to differentiate intermittent from sustained hypoxemia, we included events between 4 and $180 \mathrm{~s}$ (1). The exact threshold below which IH is clinically significant is controversial. A drop in $\mathrm{SpO}_{2}$ to less than $80 \%$ is widely considered to be clinically relevant $(1,2,6)$. Therefore, the primary outcome measure was defined as percent time spent with $\mathrm{SpO}_{2}$ below $80 \%$ (\%time- $\mathrm{SpO}_{2}<80$ ). The secondary outcome measure was defined as the number of severe $\mathrm{IH}$ events with $\mathrm{SpO}_{2}$ less than $80 \%\left(\mathrm{IH}-\mathrm{SpO}_{2}<80\right)$. Other outcome measures such as length of stay and neonatal morbidities were collected.

Pulse oximeters were equipped with serial data recorders (Acumen Instruments Corp.) for continuous data collection. Novel programs were utilized to filter and analyze data (Matlab, Natick, MA, USA) (1, 33). Data with artifacts were excluded. Only $\mathrm{SpO}_{2}$ data with good signal were included in the analyses. Preterm infants less than 30 weeks GA were included. Infants with major congenital malformations were excluded.

Data related to substance misuse and tobacco use were retrospectively collected from medical charts. If a mother chronically used prenatal opioids and/or the maternal/neonatal drug screens were positive for opioids, then the infant was considered for screening. Infants were then excluded from the study if the mother used tobacco, alcohol, or other drugs (such as cannabis); i.e., in order to assess for isolated opioid exposure, patients with any other exposure were excluded. Infants in our cohort who were not exposed to opioids, tobacco, or other drugs served as controls. Neonatal meconium or urine drug screens are performed in the immediate newborn period. Positive drug screens due to opioids and other medications used for pain or sedation during delivery were excluded, as they do not represent prenatal misuse. Tobacco and alcohol use were collected from mothers' medical records, as the toxicology screens at our hospital do not test for alcohol or tobacco exposure. The study was approved by the University of Kentucky Institutional Review Board, and informed consent was obtained prior to $\mathrm{SpO}_{2}$ data acquisition.

\section{Statistical Analysis}

Descriptive statistics for continuous variables are presented as either the mean with SD or median with interquartile range, and frequencies and percentages are given for categorical variables. Two-sample $t$-tests and Wilcoxon two-sample tests were used to compare opioid exposure to non-exposure with respect to continuous variables, and chi-square or Fisher's exact tests were used for categorical variables. To compare opioid exposure to non-exposure with respect to IH measures over time, we utilized multivariate Gaussian linear modeling in order to account for repeated measurements from subjects, and to adjust for the potential confounders of GA, birth weight, APGAR score at 5 min of life, gender, and the use of prenatal steroids. In order to meet statistical assumptions in these models, the square root of the IH measures was taken. Furthermore, weekly observations were weighted by the percentage of time IH was tracked during the given week. Analyses were conducted in SAS version 9.4 (SAS Institute, Cary, NC, USA), and all tests were two-sided with a $5 \%$ significance level.

\section{RESULTS}

Of the 127 infants in our database with complete data sets, 19.7, 29.1 , and $4.7 \%$ were prenatally exposed to opioids, tobacco, and cannabis, respectively. None were exposed to alcohol, cocaine, and other illicit drugs. Opioid exposed infants were positive for 
buprenorphine metabolites (64\%), oxycodone (16\%), and other opioids such as heroin and fentanyl (20\%). A total of 82 infants qualified for analysis as they were either unexposed to any illicit drug/tobacco $(n=68)$ or exposed to opioids only $(n=14)$. Figure 1 presents the flow diagram for patient eligibility and exclusion.

There were no significant differences in baseline characteristics as presented in Table 1. The mean GA was 27 weeks in both groups. There were no significant differences in birth weight, gender, and Apgar scores at $5 \mathrm{~min}$ of life. The vast majority of infants received prenatal steroids with no difference between groups. There were no significant differences in respiratory outcomes and neonatal morbidities between groups as presented in Table 2. Our cohort included preterm infants less than 30 weeks GA. Essentially all infants had respiratory distress syndrome and received surfactant. Severe bronchopulmonary dysplasia, postnatal steroids use for lung disease, and oxygen need at 28 days, 36 weeks postmenstrual age, and at discharge did not differ between opioid exposed and unexposed groups (all $p=\mathrm{NS}$ ). Other neonatal morbidities such as patent ductus arteriosus, late onset sepsis, and necrotizing enterocolitis did not differ between groups (all $p=\mathrm{NS}$ ). None of the exposed infants died versus nine deaths in the unexposed

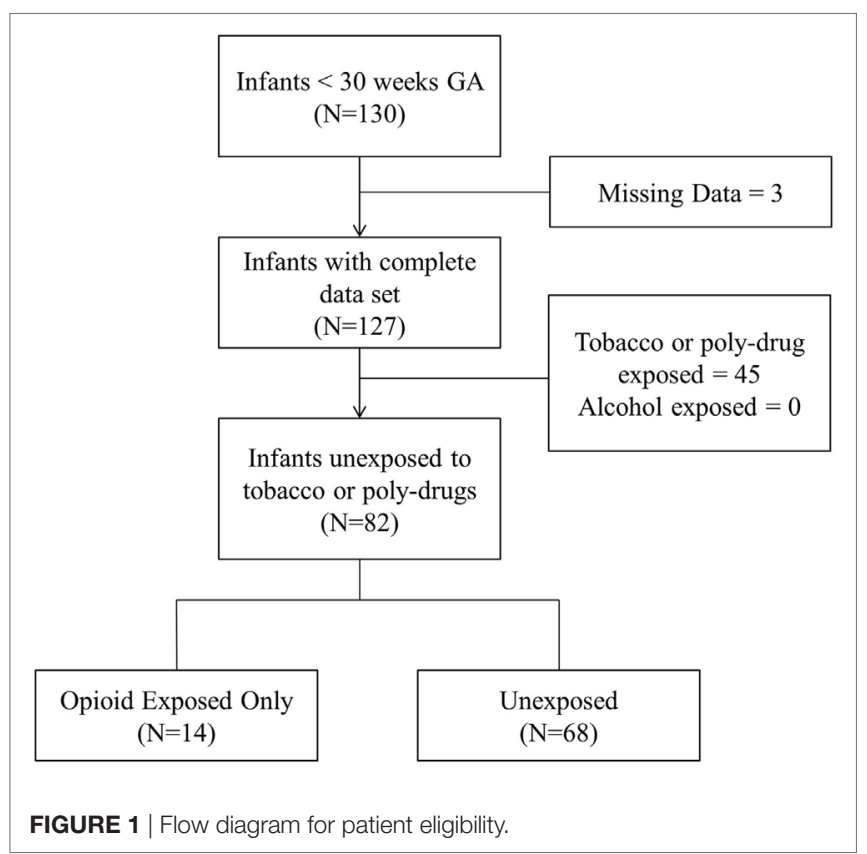

TABLE 1 | Baseline characteristics.

\begin{tabular}{lccc}
\hline & Opioid exposed & Unexposed & \multirow{2}{*}{$\boldsymbol{p}$-Value } \\
\cline { 2 - 3 } & $\boldsymbol{N}=\mathbf{1 4}$ & $\boldsymbol{N}=\mathbf{6 8}$ & \\
\hline Gestational age (weeks) & $27.0 \pm 2.1$ & $27.0 \pm 1.6$ & 0.97 \\
Birth weight (g) & $948 \pm 263$ & $928 \pm 247$ & 0.79 \\
Male & $6(43 \%)$ & $23(34 \%)$ & 0.54 \\
Apgar 5 min & $7(6,7.5)$ & $6(5,7)$ & 0.21 \\
Prenatal steroids & $12(86 \%)$ & $61(91 \%)$ & 0.62 \\
\hline
\end{tabular}

Mean $\pm S D$, median (interquartile range). group $(p=0.35)$. The median length of stay was 17 days longer in the opioid group (85 days) compared to unexposed group (68 days); however, the results were not statistically significant $(p=0.32)$.

There was a statistically significant increase in our primary outcome measure, \%time- $\mathrm{SpO}_{2}<80$, as represented in Figure 2. The estimated difference in the means of the square root of $\%$ time- $\mathrm{SpO}_{2}<80$ was 0.23 (95\% CI: $0.03,0.43, p=0.03$ ). The mean number of IH events was estimated to be 2.95 (95\% CI: $-0.35,6.25, p$-value $=0.08$ ) higher in the opioid exposed group, as represented in Figure 3; however, this did not reach statistical significance. Note that these results represent the square root of means in order to meet statistical assumptions in these models; estimated medians for IH measures are calculated using our model results and are presented in Figures $\mathbf{2 B}$ and 3B. Given increased death in the unexposed group, we then analyzed data excluding deaths, and results were similar. Specifically, there was a statistically significant increase in our primary outcome measure (\%time-SpO $\mathrm{S}_{2}<80$ ) in the opioid exposed compared to the unexposed group, with an estimated mean difference (square root) of 0.24 (95\% CI: 0.05, 0.44, $p$-value $=0.02$ ). Furthermore, the mean number of IH events was estimated to be 2.98 (95\% CI: $-0.20,6.16$, $p$-value $=0.07$ ) higher in the opioid exposed group, not quite reaching statistical significance.

\section{DISCUSSION}

These results suggest that prenatal opioid exposure is associated with increased $\mathrm{IH}$ measures compared to unexposed preterm infants. This study has two main findings. First, interestingly, the increased IH measures in opioid exposed infants persisted beyond the early postnatal period. Preterm infants were continuously monitored with high-resolution pulse oximeters during the first 2 months of life. Second, we had the unique opportunity to assess the relationship between isolated opioid exposure and respiratory instability in preterm infants. It was challenging in the past to assess the relationship between isolated prenatal opioid

TABLE 2 | Neonatal morbidities and outcomes.

\begin{tabular}{lccc}
\hline & $\begin{array}{c}\text { Opioid } \\
\text { exposed }\end{array}$ & Unexposed & p-Value \\
\cline { 2 - 3 } & $\mathbf{N = 1 4}$ & $\mathbf{N = 6 8}$ & \\
\hline Received surfactant & $14(100 \%)$ & $62(91 \%)$ & 0.58 \\
Respiratory distress syndrome & $14(100 \%)$ & $67(99 \%)$ & 1 \\
Oxygen at 28 days of life & $10(71 \%)$ & $39(57 \%)$ & 1 \\
Oxygen at 36 weeks corrected age & $7(50 \%)$ & $19(28 \%)$ & 0.26 \\
Oxygen at discharge & $9(64 \%)$ & $30(44 \%)$ & 0.18 \\
Severe bronchopulmonary dysplasia & $9(64 \%)$ & $27(46 \%)$ & 0.21 \\
Postnatal steroids use for lung disease & $6(43 \%)$ & $19(29 \%)$ & 0.35 \\
Pneumothorax & $1(7 \%)$ & $2(3 \%)$ & 0.43 \\
Patent ductus arteriosus & $8(57 \%)$ & $24(35 \%)$ & 0.13 \\
Necrotizing enterocolitis & $0(0 \%)$ & $2(3 \%)$ & 1 \\
Late onset sepsis & $3(21 \%)$ & $9(13 \%)$ & 0.43 \\
Mortality & $0(0 \%)$ & $9(13 \%)$ & 0.35 \\
Length of stay (days) & $85(59,101)$ & $68(56,91)$ & 0.32 \\
\hline
\end{tabular}

Frequency (\%), median (interquartile range). 


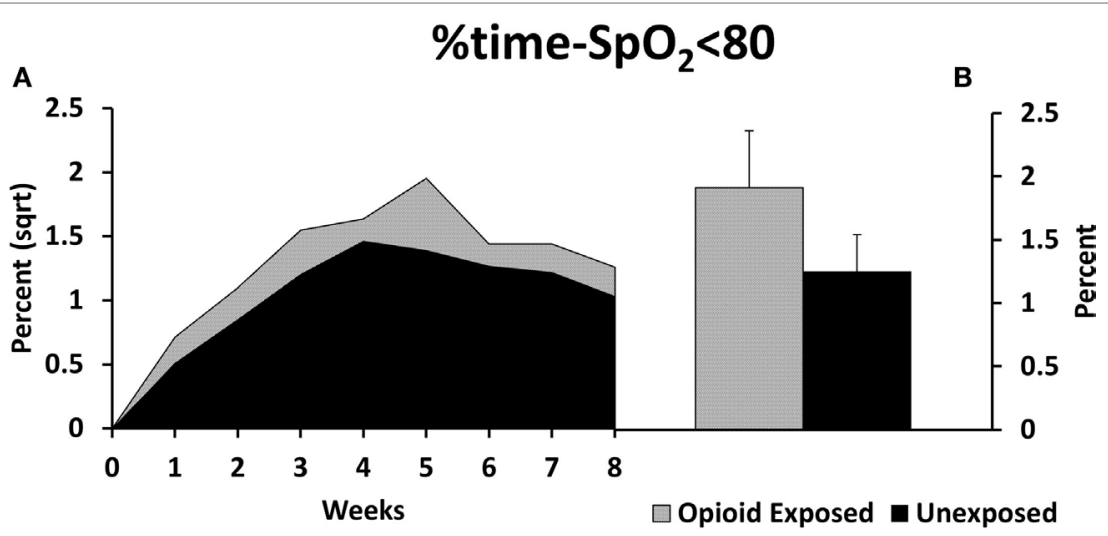

FIGURE 2 | (A) Preterm infants exposed to prenatal opioids had increased time spent with oxygen saturation less than $80 \%$ (\%time-SpO 2 < 80 ) compared to unexposed infants $(p=0.03)$. The model adjusted for gestational age, birth weight, gender, prenatal steroids, and Apgar scores at 5 min of life. (B) This figure demonstrates the estimated average \%time- $\mathrm{SpO}_{2}<80$ medians in both groups calculated using the adjusted model results. Sqrt, square root.

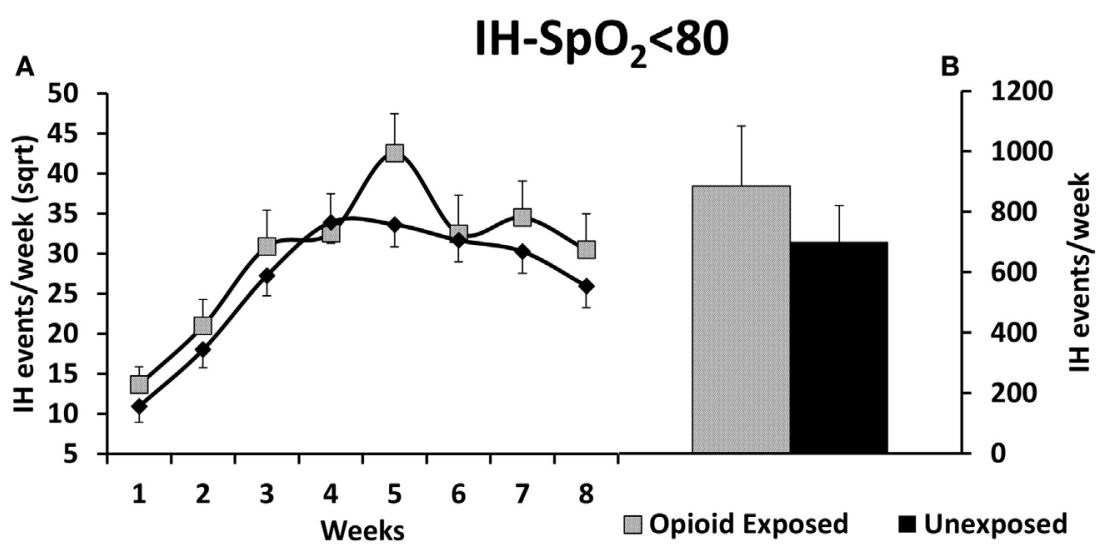

FIGURE 3 | (A) Preterm infants exposed to prenatal opioids did not have a significant increase in number of intermittent hypoxemia (IH) events per week (IH$\mathrm{SpO}_{2}<80$ ) compared to unexposed infants $(p=0.08)$. The model adjusted for gestational age, birth weight, gender, prenatal steroids, and Apgar scores at 5 min of life. (B) This figure demonstrates the estimated average $\mathrm{IH}-\mathrm{SpO} \mathrm{O}_{2}<80$ medians of opioid exposed versus unexposed preterm infants calculated using the adjusted model results. Sqrt, square root.

exposure and respiratory outcomes/ $\mathrm{IH}$, as the majority of women who use opioids also smoke or misuse poly-drugs. Given our cohort demographics, we had the ability to report this association in infants exposed to opioids only.

Another interesting secondary finding in our study is the steady increase in $\mathrm{IH}$ in the first month of life before plateauing and then decreasing. This natural progression of $\mathrm{IH}$ has been described before from another cohort of preterm infants less than 28 weeks GA $(1,2)$. Our study replicates this finding from a new cohort of preterm infants less than 30 weeks GA. The rise in IH may be related to peripheral chemoreceptor dysregulation and development of lung disease (34).

Patients in our opioid exposed and unexposed groups did not significantly vary in terms of baseline characteristics (such as age, weight, gender) and neonatal morbidities (such as lung disease, patent ductus arteriosus, late onset sepsis, and necrotizing enterocolitis). In addition, we adjusted in the model for factors that may influence oxygenation in preterm infants such as GA and prenatal steroids. The finding of nine deaths in the unexposed group compared to no deaths in the opioid exposed group may be due to chance. Secondary analyses excluding deaths showed similar results with increased $\mathrm{IH}$ in the opioid exposed group. A significant secondary finding in this study is the high prevalence of tobacco and drug exposure in our cohort of preterm infants. The frequency of opioid exposure in our preterm population is higher than previously reported, thus creating urgency toward addressing this significant problem in this vulnerable patient population (10, 12-15).

There are multiple proposed mechanisms by which prenatal opioid exposure may affect breathing patterns and subsequent persistent IH in preterm infants. Prenatal opioid exposure alters the response to carbon dioxide and depresses central respiratory control centers (31,35-38); a main driver for respiratory output. Olsen and Lees demonstrated a blunted response to carbon 
dioxide in methadone exposed infants compared to controls (31). Ali et al. compared the response to hypercarbia among three groups of term patients who were exposed to tobacco/ substance misuse, tobacco alone, and unexposed controls. The authors showed a lower increase in central respiratory drive in response to hypercarbia in infants exposed to substance misuse as compared to tobacco alone and unexposed controls (35). Another mechanism that explains our results may be related to in utero hypoxia related to opioids. Prenatal opioids, especially street heroin, cause chronic intrauterine hypoxia leading to brainstem gliosis, resulting in injury to the central respiratory network. This may lead to respiratory instability and subsequent IH (36). Finally, data from animal models showed that exposure to opioid agonists caused downregulation of placental neurotransmitter receptors (39). Abnormalities or depletion of receptor sites, especially if the same process occurs in the fetal brain, could impair the function of the normal neonatal respiratory control network leading to frequent or prolonged apnea and subsequent $\mathrm{IH}$.

Many studies have assessed the impact of prenatal opioid exposure on sudden infant death syndrome (SIDS) in infants with controversial results. This study does not address SIDS; rather, it focuses on $\mathrm{IH}$, the end result of apnea of prematurity. However, the mechanism by which prenatal opioid exposure is associated with increased SIDS and IH may be similar. Although our study period focused on the inpatient setting, it is plausible that opioid exposed infants continue to have increased cardiorespiratory events/IH after discharge. Interestingly, compared to unexposed infants, opioid exposed infants had a trend toward longer length of stay ( 68 versus 85 days, $p=$ NS), which may be related, in part, to persistent cardiorespiratory events.

A major limitation of this study is that data related to exposure were retrospectively collected. Another limitation is a lack of reporting daily caffeine use and daily respiratory support settings. At our center, virtually all infants with GA less than 30 weeks are started on caffeine therapy. Furthermore, our study focused on $\mathrm{IH}$ events and lacked reporting of apnea and bradycardia events. Lack of addressing heart rate is a limitation since bradycardia events may be associated with poor long-term outcomes (6). Another limitation is the small sample size; however, our sample size of isolated opioid exposure is relatively large compared to existing literature. This is a single center study; hence, our results may not be generalizable. Finally, we did not compare the long-term neurodevelopmental outcomes for exposed versus unexposed infants.

\section{CONCLUSION}

There is rising evidence linking $\mathrm{IH}$ to neonatal morbidities and impairment. However, the exact threshold (frequency, duration, severity) by which IH leads to injury in preterm infants needs further investigation; i.e., any increase in IH may be associated with impairment in preterm infants. Furthermore, there is a need to understand factors, such as prenatal opioid exposure, that may influence IH and subsequently increase neonatal morbidities. In this study, we show an association between prenatal opioid exposure and increased IH measures in preterm infants. Studies to address the relationship between opioid exposures, $\mathrm{IH}$, and long-term neurodevelopmental outcomes are imperative. Given the rising epidemic of opioid misuse in the USA, understanding the relationship between opioid exposure, IH and long-term impairment is imperative. A larger prospective study aimed at understanding these relationships may have a direct impact on short- and long-term management of preterm infants.

\section{ETHICS STATEMENT}

This study was carried out in accordance with the recommendations of University of Kentucky Institutional Review Board (IRB). A written informed consent was obtained from all subjects included in this study. All subjects gave written informed consent in accordance with the Declaration of Helsinki. The protocol was approved by the University of Kentucky IRB.

\section{AUTHOR CONTRIBUTIONS}

EA designed and conceptualized the study and was actively involved in the enrollment, data collection, as well as analysis and interpretation of the results. He drafted the initial manuscript and wrote the final manuscript as submitted. PW was involved in conceptualization of the study and performed the statistical analyses. He also critically reviewed the manuscript and made the final approval manuscript as submitted. AP, AS, DM, and AG were involved in the conceptualization of the study, data collection, as well as analysis and interpretation of the results. They critically reviewed the manuscript and approved the final manuscript as submitted. AP was involved in the conceptualization of the study, the data acquisition software development, as well as in the analysis and interpretation of the results. He critically reviewed the manuscript and approved the final manuscript as submitted. $\mathrm{HB}$ and PG were involved in the conceptualization of the study as well as analysis and interpretation of the results. They critically reviewed the manuscript and approved the final manuscript as submitted.

\section{ACKNOWLEDGMENTS}

This project was supported by funds from the Gerber Foundation, Children's Miracle Network and the National Center for Research Resources, UL1RR033173, and is now at the National Center for Advancing Translational Sciences. The content is solely the responsibility of the authors and does not necessarily represent the official views of the NIH. The authors thank the support of Katrina Ibonia MD, Enrique Gomez-Pomar MD, Vicki Whitehead RN CCRC, Kimberly Walker BSN, Alisa (Beth) McKinney-Whitlock CCRP, Sean Carpenter BSBE, John Bauer PhD, NICU nurses, research nurses and staff, and neonatology faculty and fellows at the Division of Neonatology, University of Kentucky.

\section{FUNDING}

The study was funded by: (1) The Gerber Foundation, (2) Children's Miracle Network, and (3) National Center for Research Resources, UL1RR033173, and is now at the National Center for Advancing Translational Sciences. 


\section{REFERENCES}

1. Abu Jawdeh EG, Martin RJ, Dick TE, Walsh MC, Di Fiore JM. The effect of red blood cell transfusion on intermittent hypoxemia in ELBW infants.J Perinatol (2014) 34(12):921-5. doi:10.1038/jp.2014.115

2. Di Fiore JM, Bloom JN, Orge F, Schutt A, Schluchter M, Cheruvu VK, et al. A higher incidence of intermittent hypoxemic episodes is associated with severe retinopathy of prematurity. J Pediatr (2010) 157(1):69-73. doi:10.1016/j.jpeds.2010.01.046

3. Rhein LM, Dobson NR, Darnall RA, Corwin MJ, Heeren TC, Poets CF, et al. Effects of caffeine on intermittent hypoxia in infants born prematurely: a randomized clinical trial. JAMA Pediatr (2014) 168(3):250-7. doi:10.1001/ jamapediatrics.2013.4371

4. Darnall RA, Chen X, Nemani KV, Sirieix CM, Gimi B, Knoblach S, et al. Early postnatal exposure to intermittent hypoxia in rodents is proinflammatory, impairs white matter integrity, and alters brain metabolism. Pediatr Res (2017) 82(1):164-72. doi:10.1038/pr.2017.102

5. Pozo ME, Cave A, Koroglu OA, Litvin DG, Martin RJ, Di Fiore J, et al. Effect of postnatal intermittent hypoxia on growth and cardiovascular regulation of rat pups. Neonatology (2012) 102(2):107-13. doi:10.1159/000338096

6. Poets CF, Roberts RS, Schmidt B, Whyte RK, Asztalos EV, Bader D, et al. Association between intermittent hypoxemia or bradycardia and late death or disability in extremely preterm infants. JAMA (2015) 314(6):595-603. doi:10.1001/jama.2015.8841

7. Schmidt B, Whyte RK, Asztalos EV, Moddemann D, Poets C, Rabi Y, et al. Effects of targeting higher vs lower arterial oxygen saturations on death or disability in extremely preterm infants: a randomized clinical trial. JAMA (2013) 309(20):2111-20. doi:10.1001/jama.2013.5555

8. Janvier A, Khairy M, Kokkotis A, Cormier C, Messmer D, Barrington KJ. Apnea is associated with neurodevelopmental impairment in very low birth weight infants. J Perinatol (2004) 24(12):763-8. doi:10.1038/sj.jp.7211182

9. Pillekamp F, Hermann C, Keller T, von Gontard A, Kribs A, Roth B. Factors influencing apnea and bradycardia of prematurity - implications for neurodevelopment. Neonatology (2007) 91(3):155-61. doi:10.1159/000097446

10. Wang X, Zhu Y, Dave CV, Alrwisan AA, Voils SA, Winterstein AG. Trends of neonatal abstinence syndrome epidemic and maternal risk factors in Florida. Pharmacotherapy (2017) 37(7):806-13. doi:10.1002/phar.1947

11. Jiang R, Lee I, Lee TA, Pickard AS. The societal cost of heroin use disorder in the United States. PLoS One (2017) 12(5):e0177323. doi:10.1371/journal. pone. 0177323

12. Corr TE, Hollenbeak CS. The economic burden of neonatal abstinence syndrome in the United States. Addiction (2017) 112(9):1590-9. doi:10.1111/ add. 13842

13. Patrick SW, Schumacher RE, Benneyworth BD, Krans EE, McAllister JM, Davis MM. Neonatal abstinence syndrome and associated health care expenditures: United States, 2000-2009. JAMA (2012) 307(18):1934-40. doi:10.1001/jama.2012.3951

14. Patrick SW, Davis MM, Lehman CU, Cooper WO. Increasing incidence and geographic distribution of neonatal abstinence syndrome: United States 2009 to 2012. J Perinatol (2015) 35(8):667. doi:10.1038/jp.2015.36

15. Ko JY, Patrick SW, Tong VT, Patel R, Lind JN, Barfield WD. Incidence of neonatal abstinence syndrome - 28 States, 1999-2013. MMWR Morb Mortal Wkly Rep (2016) 65(31):799-802. doi:10.15585/mmwr.mm6531a2

16. Reddy UM, Davis JM, Ren Z, Greene MF. Opioid Use in Pregnancy, Neonatal Abstinence Syndrome, and Childhood Outcomes: Executive Summary of a Joint Workshop by the Eunice Kennedy Shriver National Institute of Child Health and Human Development, American College of Obstetricians and Gynecologists, American Academy of Pediatrics, Society for Maternal-Fetal Medicine, Centers for Disease Control and Prevention, and the March of Dimes Foundation. Obstet Gynecol (2017) 130(1):10-28. doi:10.1097/ AOG.0000000000002054

17. Heller NA, Logan BA, Morrison DG, Paul JA, Brown MS, Hayes MJ. Neonatal abstinence syndrome: neurobehavior at 6 weeks of age in infants with or without pharmacological treatment for withdrawal. Dev Psychobiol (2017) 59(5):574-82. doi:10.1002/dev.21532

18. Bada HS, Sithisarn T, Gibson J, Garlitz K, Caldwell R, Capilouto G, et al. Morphine versus clonidine for neonatal abstinence syndrome. Pediatrics (2015) 135(2):e383-91. doi:10.1542/peds.2014-2377
19. Coyle MG, Salisbury AL, Lester BM, Jones HE, Lin H, Graf-Rohrmeister K, et al. Neonatal neurobehavior effects following buprenorphine versus methadone exposure. Addiction (2012) 107(Suppl 1):63-73. doi:10.1111/j. 1360-0443.2012.04040.x

20. Jansson LM, Di Pietro JA, Elko A, Williams EL, Milio L, Velez M. Pregnancies exposed to methadone, methadone and other illicit substances, and poly-drugs without methadone: a comparison of fetal neurobehaviors and infant outcomes. Drug Alcohol Depend (2012) 122(3):213-9. doi:10.1016/j. drugalcdep.2011.10.003

21. Bandstra ES, Morrow CE, Mansoor E, Accornero VH. Prenatal drug exposure: infant and toddler outcomes. J Addict Dis (2010) 29(2):245-58. doi:10.1080/10550881003684871

22. Velez ML, Jansson LM, Schroeder J, Williams E. Prenatal methadone exposure and neonatal neurobehavioral functioning. Pediatr Res (2009) 66(6):704-9. doi:10.1203/PDR.0b013e3181bc035d

23. Witt CE, Rudd KE, Bhatraju P, Rivara FP, Hawes SE, Weiss NS. Neonatal abstinence syndrome and early childhood morbidity and mortality in Washington state:aretrospectivecohortstudy.J Perinatol(2017)37(10):1124-9.doi:10.1038/ jp.2017.106

24. Koehntop DE, Rodman JH, Brundage DM, Hegland MG, Buckley JJ. Pharmacokinetics of fentanyl in neonates. Anesth Analg (1986) 65(3):227-32. doi:10.1213/ 00000539-198603000-00002

25. Robinson DM, Peebles KC, Kwok H, Adams BM, Clarke LL, Woollard GA, et al. Prenatal nicotine exposure increases apnoea and reduces nicotinic potentiation of hypoglossal inspiratory output in mice. J Physiol (2002) 538 (Pt 3):957-73. doi:10.1113/jphysiol.2001.012705

26. Hanrahan JP, Tager IB, Segal MR, Tosteson TD, Castile RG, Van Vunakis H, et al. The effect of maternal smoking during pregnancy on early infant lung function. Am Rev Respir Dis (1992) 145(5):1129-35. doi:10.1164/ajrccm/145.5.1129

27. Hafstrom O, Milerad J, Sandberg KL, Sundell HW. Cardiorespiratory effects of nicotine exposure during development. Respir Physiol Neurobiol (2005) 149(1-3):325-41. doi:10.1016/j.resp.2005.05.004

28. Ueda Y, Stick SM, Hall G, Sly PD. Control of breathing in infants born to smoking mothers. J Pediatr (1999) 135(2 Pt 1):226-32. doi:10.1016/ S0022-3476(99)70026-0

29. Galland BC, Taylor BJ, Bolton DP, Sayers RM. Respiratory responses to hypoxia/hypercapnia in small for gestational age infants influenced by maternal smoking. Arch Dis Child Fetal Neonatal Ed (2003) 88(3):F217-22. doi:10.1136/fn.88.3.F217

30. Silvestri JM, Long JM, Weese-Mayer DE, Barkov GA. Effect of prenatal cocaine on respiration, heart rate, and sudden infant death syndrome. Pediatr Pulmonol (1991) 11(4):328-34. doi:10.1002/ppul.1950110409

31. Olsen GD, Lees MH. Ventilatory response to carbon dioxide of infants following chronic prenatal methadone exposure. J Pediatr (1980) 96(6):983-9. doi:10.1016/S0022-3476(80)80622-6

32. Wingkun JG, Knisely JS, Schnoll SH, Gutcher GR. Decreased carbon dioxide sensitivity in infants of substance-abusing mothers. Pediatrics (1995) 95(6):864-7.

33. Gomez-Pomar E, Makhoul M, Westgate PM, Ibonia KT, Patwardhan A, Giannone PJ, et al. Relationship between perfusion index and patent ductus arteriosus in preterm infants. Pediatr Res (2017) 81(5):775-9. doi:10.1038/ pr.2017.10

34. Martin RJ, Di Fiore JM, Walsh MC. Hypoxic episodes in bronchopulmonary dysplasia. Clin Perinatol (2015) 42(4):825-38. doi:10.1016/j.clp.2015. 08.009

35. Ali K, Wolff K, Peacock JL, Hannam S, Rafferty GF, Bhat R, et al. Ventilatory response to hypercarbia in newborns of smoking and substance-misusing mothers. Ann Am Thorac Soc (2014) 11(6):933-8. doi:10.1513/ AnnalsATS.201403-124OC

36. Kandall SR, Gaines J. Maternal substance use and subsequent sudden infant death syndrome (SIDS) in offspring. Neurotoxicol Teratol (1991) 13(2):235-40. doi:10.1016/0892-0362(91)90016-P

37. Ward SL, Schuetz S, Kirshna V, Bean X, Wingert W, Wachsman L, et al. Abnormal sleeping ventilatory pattern in infants of substance-abusing mothers. Am J Dis Child (1986) 140(10):1015-20.

38. Mueller RA, Lundberg DB, Breese GR, Hedner J, Hedner T, Jonason J. The neuropharmacology of respiratory control. Pharmacol Rev (1982) 34(3):255-85. 
39. Perry BD, Pesavento DJ, Kussie PH, U'Prichard DC, Schnoll SH. Prenatal exposure to drugs of abuse in humans: effects on placental neurotransmitter receptors. Neurobehav Toxicol Teratol (1984) 6(4):295-301.

Conflict of Interest Statement: The authors declare that the research was conducted in the absence of any commercial or financial relationships that could be construed as a potential conflict of interest.
Copyright (C) 2017 Abu Jawdeh, Westgate, Pant, Stacy, Mamilla, Gabrani, Patwardhan, Bada and Giannone. This is an open-access article distributed under the terms of the Creative Commons Attribution License (CC BY). The use, distribution or reproduction in other forums is permitted, provided the original author(s) or licensor are credited and that the original publication in this journal is cited, in accordance with accepted academic practice. No use, distribution or reproduction is permitted which does not comply with these terms. 